\title{
Chronic wasting disease in Europe: new strains on the horizon
}

\author{
Michael Andreas Tranulis ${ }^{1 *}$ @ , Dolores Gavier-Widén ${ }^{2,3}$, Jørn Våge ${ }^{4}$, Maria Nöremark², Sirkka-Liisa Korpenfelt ${ }^{5}$, \\ Maria Hautaniemi ${ }^{5}$, Laura Pirisinu ${ }^{6}$, Romolo Nonno ${ }^{6}$ and Sylvie Lafond Benestad ${ }^{4}$
}

\begin{abstract}
Prion diseases are fatal neurodegenerative disorders with known natural occurrence in humans and a few other mammalian species. The diseases are experimentally transmissible, and the agent is derived from the host-encoded cellular prion protein (PrPC), which is misfolded into a pathogenic conformer, designated PrPSc (scrapie). Aggregates of PrPSc molecules, constitute proteinaceous infectious particles, known as prions. Classical scrapie in sheep and goats and chronic wasting disease (CWD) in cervids are known to be infectious under natural conditions. In CWD, infected animals can shed prions via bodily excretions, allowing direct host-to-host transmission or indirectly via prion-contaminated environments. The robustness of prions means that transmission via the latter route can be highly successful and has meant that limiting the spread of CWD has proven difficult. In 2016, CWD was diagnosed for the first time in Europe, in reindeer (Rangifer tarandus) and European moose (Alces alces). Both were diagnosed in Norway, and, subsequently, more cases were detected in a semi-isolated wild reindeer population in the Nordfjella area, in which the first case was identified. This population was culled, and all reindeer (approximately 2400) were tested for CWD; 18 positive animals, in addition to the first diagnosed case, were found. After two years and around 25,900 negative tests from reindeer (about 6500 from wild and 19,400 from semi-domesticated) in Norway, a new case was diagnosed in a wild reindeer buck on Hardangervidda, south of the Nordfjella area, in 2020. Further cases of CWD were also identified in moose, with a total of eight in Norway, four in Sweden, and two cases in Finland. The mean age of these cases is 14.7 years, and the pathological features are different from North American CWD and from the Norwegian reindeer cases, resembling atypical prion diseases such as Nor98/atypical scrapie and $\mathrm{H}$ - and L-forms of BSE. In this review, these moose cases are referred to as atypical CWD. In addition, two cases were diagnosed in red deer (Cervus elaphus) in Norway. The emergence of CWD in Europe is a threat to European cervid populations, and, potentially, a food-safety challenge, calling for a swift, evidence-based response. Here, we review data on surveillance, epidemiology, and disease characteristics, including prion strain features of the newly identified European CWD agents.
\end{abstract}

Keywords: CWD, Deer, Fennoscandia, Moose, Nordic countries, Prion disease, Red deer, Reindeer

\section{Background}

Chronic wasting disease (CWD) is a fatal neurodegenerative disease affecting species of the Cervidae family. It is a prion disease, of which human Creutzfeldt-Jakob

\footnotetext{
*Correspondence: Michael.Tranulis@nmbu.no

${ }^{1}$ Department of Preclinical Sciences and Pathology, Faculty of Veterinary

Medicine, Norwegian University of Life Sciences, Post Box 5003, Ås, Norway

Full list of author information is available at the end of the article
}

disease, scrapie in sheep and goats, and bovine spongiform encephalopathy (BSE) in cattle are well known [1]. In these maladies, the host-encoded cellular prion protein $\left(\mathrm{PrP}^{\mathrm{C}}\right)$ is misfolded into an aggregation-prone conformer called $\mathrm{PrP}^{\mathrm{Sc}}$ (scrapie), aggregates of which constitute transmissible prions [2,3]. Misfolded PrP conformers interact with $\operatorname{PrP}^{\mathrm{C}}$ molecules and convert these into three-dimensional copies of the misfolded conformer, and these can have neurotoxic effects. For typical 
prion-induced neurotoxicity to occur, $\operatorname{PrP}^{\mathrm{C}}$ (i.e., the substrate for prion propagation), must be present at the neuronal cell surface $[4,5]$ to which it is normally attached with a glycosylphosphatidylinositol (GPI) anchor [6]. Animals without $\operatorname{PrP}^{\mathrm{C}}$ are completely resistant to prion infection [5, 7]. Investigations of animals devoid of $\operatorname{PrP}^{\mathrm{C}}$, either transgenic [8] or naturally occurring [9], have identified a physiological role for $\operatorname{PrP}^{\mathrm{C}}$ in maintenance of peripheral nerve myelin.

Misfolding of $\mathrm{PrP}^{\mathrm{C}}$ can occur spontaneously or be caused by somatic or germ-line mutations in the gene encoding $\mathrm{PrP}^{\mathrm{C}}$, giving rise to sporadic or inherited prion diseases [10]. Exposure to exogenous prions, either through experimental challenge, iatrogenic or natural infection, can also induce prion disease. Indeed, the transmissibility of prion diseases was recognized early, and the diseases were called transmissible spongiform encephalopathies (TSE) [11]. Although, uniformly transmissible, only classical scrapie in small ruminants [12], CWD in cervids $[13,14]$, and the more recently discovered prion disease of dromedary camels [15], can transmit horizontally under natural circumstances. A commonality of the infectious and environmentally transmissible prion diseases is the accumulation of prions in peripheral tissues, most notably lymphoid organs, including those along the gastro-intestinal tract, facilitating the release of prions in excretions [16-21]. Although prion infectivity has been demonstrated in peripheral tissues, including in sporadic prion diseases in both humans [22] and atypical prion diseases in animals [23], prion release to the surroundings does not normally appear to reach the levels needed for horizontal transmission. The distinction between sporadic and infectious disease aetiology is fundamentally important in assessment and management of animal prion diseases. This has been demonstrated most clearly in classical versus Nor98/atypical scrapie, with the former transmitting horizontally between genetically susceptible animals and the latter occurring sporadically in old animals [24, 25]. Whilst infectious classical scrapie has been effectively combatted by stamping out, imposing limitations on animal movements, and, importantly, by selective breeding for increased resistance [26], such efforts have had minimal impact on the sporadic occurrence of Nor98/atypical scrapie.

CWD, as characterized from North America during the last 50 years, has clearly presented as an infectious disease, transmitting horizontally within and between several cervid species, in many instances with similar efficiency as that of classical scrapie in sheep [13]. Accordingly, the presence of CWD prions has been observed to be prominent in peripheral tissues, and the release of CWD infectivity in saliva [27, 28], urine $[29,30]$, and faeces [31] has been documented even at preclinical stages. Outbreaks of CWD caused by prion-contaminated environments have also occurred [32-36] and indirect transmission through the environment may, in heavily contaminated areas, be the main mode of transmission. CWD has spread relentlessly in North America and is currently present in 26 US states and three Canadian provinces [37], affecting both farmed and free-ranging deer, particularly white-tailed deer (Odocoileus virginianus), mule deer (Odocoileus hemionus), and rocky mountain elk (Cervus canadensis nelsoni). A few cases in North American moose (Alces alces shirasi) have also been recorded [38], and a single case has been diagnosed in a captive reindeer (Rangifer tarandus) in Northern Illinois [39].

Prions come in varieties known as strains, all of which consist of misfolded and aggregated PrP, but folded and arranged differently [40-47]. The differences may be structurally subtle, but nevertheless clinically and epidemiologically significant, affecting the species transmission spectrum and disease manifestation. Prions are characterized at many levels: by primary host, organ distribution, and pattern of $\mathrm{PrP}^{\mathrm{Sc}}$ aggregates, by biochemical characterisation of $\mathrm{PrP}^{\mathrm{Sc}}$ and, importantly, in bioassays in defined rodent models, such as bank voles (Myodes glareolus) [48, 49], and transgenic mice [50-52]. Initial identification and detailed characterization of prion strains depend on bioassays. When transmitting a primary isolate to a rodent model, the attack rate and incubation period are recorded. Furthermore, the pathology and biochemical properties of $\mathrm{PrP}^{\mathrm{Sc}}$ as revealed by western blot (WB) i.e., glycoprofile (the abundance of glycosylated forms) and fragment size of $\mathrm{PrP}^{\mathrm{Sc}}$ following treatment with proteinase $\mathrm{K}$, provide valuable information about the strain [53]. The proteinase $\mathrm{K}$ resistant fragments of $\mathrm{PrP}^{\mathrm{Sc}}$ analysed in WB are referred to as $\operatorname{PrP}^{\text {res }}$ (resistant) in this paper. Upon rounds of sub-passages in the rodent model, the prion strain will adapt to its new host and attack rates will often reach $100 \%$. Simultaneously, the incubation period will drop and stabilize to a level that is reproducible and characteristic for the given strain. Thus, in contrast to bioassays of some other pathogens, such as viruses or bacteria, bioassays of prions change the pathogen itself both conformationally and functionally; some features are lost, whereas others are conserved and/or gained in the process [40]. Although, tedious and imprecise compared with modern nucleic acid-based molecular typing of pathogens, bioassays in well-defined rodent models are currently the best tools available for prion strain characterization. The molecular mechanisms and dynamics concerning hostpathogen interactions are also incompletely understood for prions. For instance, mechanisms dictating tissue 
tropism of prions, or their potential to undergo divergent or convergent evolution, remain largely unknown.

The first reports comparing European CWD isolates from wild reindeer [54] and moose have now been published $[55,56]$, showing that these differ from each other and from North American CWD strains. Further, data suggest that sub-strains might be present among the European moose CWD cases [55].

The purpose of this review is to provide an update of the current situation with emergence of CWD in Northern Europe, and, specifically, to address the issue of novel CWD strains and atypical variants of the disease.

\section{Search strategy}

This critical review is based on searches in databases PubMed (https://pubmed.ncbi.nlm.nih.gov/) using the terms; "chronic wasting disease" [Title/Abstract] AND/ OR "CWD" AND/OR "Norway" AND/OR "Europe", "Sweden", "Nordic countries". Abstracts of articles identified were evaluated for relevance to the topic. Scientific opinions and governmental advice from European and national working groups also include comprehensive literature searches and evaluations, and these were also a source of information. Data from EU, Norwegian, Swedish, and Finnish surveillance databases and diagnostic reports from relevant authorities have been retrieved. Finally, some unpublished results from ongoing investigations have been made available through personal communication.

\section{CWD surveillance in Fennoscandia before and after first detection in 2016 \\ Norway}

Data on surveillance for CWD in Norway have since 2005 been reported in annual reports [57]. Prior to detection of CWD in 2016 [54], 2159 cervids had been tested in Norway. Since only ten of these were wild reindeer, efforts were made to increase sampling of wild reindeer populations. Upon detection of CWD in reindeer and moose, surveillance was intensified [58-60], reaching 127,216 Norwegian cervids tested by March 2021 (Table 1) [61].

\section{Sweden}

With the exception of EU-regulated active surveillance 2007-2010 [62], surveillance of CWD in Sweden was passive until 2016, based on reporting and examination of animals with clinical signs. From 2016, routine sampling of cervids submitted for necropsy was introduced and archived frozen brain samples that had been collected between 2008 and 2016 were examined retrospectively [63]. From 2018, EU-regulated surveillance was introduced, focusing on cervids displaying symptoms, found dead, road killed or euthanized. The surveillance also includes slaughtered or hunted cervids found unfit for human consumption. After detection of positive cases in moose, increased surveillance in areas surrounding the positive cases has been performed, and has included healthy animals (slaughtered or hunted) found fit for human consumption [64]. Results of the surveillance are shown in Table 2.

\section{Finland}

The occurrence of CWD in wild cervids and reindeer has been monitored in Finland since 2003. The whitetailed deer population in Finland, app. 125,000 animals, originates from North America, which is why Finland targeted CWD surveillance especially to white-tailed deer during the EU-regulated surveillance in 2007-2010. From 2018, EU-regulated CWD surveillance in Finland

Table 1 CWD surveillance and diagnoses in Norway (2002-2021)

\begin{tabular}{|c|c|c|c|c|c|c|c|c|c|}
\hline & $2002-15$ & 2016 & 2017 & 2018 & 2019 & 2020 & $2021^{a}$ & Sum & $\overline{C W D}$ \\
\hline Moose (Alces alces) & 142 & $4403(\mathbf{2})$ & $5468(\mathbf{1})$ & $6705(\mathbf{1})$ & $5935(\mathbf{2})$ & $6200(1)$ & $290(\mathbf{1})$ & 29,143 & 8 \\
\hline \multicolumn{10}{|l|}{ Reindeer (Rangifer t. tarandus) } \\
\hline Semi-domesticated & 966 & 1739 & 10,940 & 12,046 & 12,937 & 6512 & 1791 & 46,931 & \\
\hline Wild & 10 & $842(4)$ & $2922(\mathbf{9})$ & $3650(6)$ & 3334 & $3213(\mathbf{1})$ & 26 & 13,997 & 20 \\
\hline \multicolumn{10}{|l|}{ Red deer (Cervus elaphus) } \\
\hline Farmed & $825^{b}$ & 129 & 444 & 643 & 571 & 823 & 118 & 3553 & \\
\hline Wild & & 2453 & $3639(\mathbf{1})$ & 7785 & 5187 & 3450 & $161(\mathbf{1})$ & 22,675 & 2 \\
\hline Fallow deer (Dama dama) & 13 & 15 & 20 & 48 & 37 & 92 & 11 & 236 & \\
\hline Roe deer (Capreolus capreolus) & 203 & 484 & 1955 & 2124 & 1692 & 1832 & 448 & 8738 & \\
\hline Cervid spp. $^{2}$ & & 82 & 271 & 655 & 454 & 406 & 65 & 1933 & \\
\hline
\end{tabular}

CWD positive diagnosis is given as number in bold in parenthesis and the total number of tested animals and the total number of diagnosed cases are also prenseted in bold in the two rightmost columns of the tables

${ }^{\text {a }}$ April 1st

${ }^{\mathrm{b}}$ Red deer was pooled wild and farmed for the years 2002-2015

${ }^{2}$ Analysis of cervid samples, but species not given at the time of analysis. Positive diagnoses of CWD in parentheses 
Table 2 CWD surveillance and diagnoses in Sweden (2007-2021)

\begin{tabular}{|c|c|c|c|c|c|c|c|c|c|}
\hline & $2007-15^{b}$ & 2016 & 2017 & 2018 & 2019 & 2020 & $2021^{\mathrm{a}}$ & Sum & CWD \\
\hline Moose (Alces alces) & 171 & 74 & 192 & 157 & $857(3)$ & $249(\mathbf{1})$ & 21 & 1721 & 4 \\
\hline Reindeer (Rangifer t. tarandus) ${ }^{c}$ & & 2 & 21 & 15 & 1965 & 991 & 107 & 3101 & \\
\hline Red deer (Cervus elaphus) & 1 & & & & & & & 1 & \\
\hline Farmed & & & & 5 & 29 & 82 & 11 & 127 & \\
\hline Wild & & 6 & 6 & 8 & 2 & 2 & & 24 & \\
\hline Fallow deer (Dama dama) & 1 & & 8 & & & 1 & & 10 & \\
\hline Roe deer (Capreolus capreolus) & 96 & 14 & 13 & 15 & 73 & 71 & 16 & 298 & \\
\hline Cervid spp. & $195^{d}$ & & & & & & & 195 & \\
\hline
\end{tabular}

CWD positive diagnosis is given as number in bold in parenthesis and the total number of tested animals and the total number of diagnosed cases are also prenseted in bold in the two rightmost columns of the tables

${ }^{\text {a }}$ March 25th

${ }^{\mathrm{b}}$ Including 270 samples examined retrospectively in 2016

c All semi-domesticated

${ }^{\mathrm{d}}$ Species known at the time of analysis, but not published in reports. Positive diagnoses of CWD in parentheses

has targeted clinically ill, fallen/road or predator killed cervids. Slaughtered or hunted cervids considered unfit for human consumption by an official veterinarian, are also sampled. Increased surveillance has been performed in areas surrounding the positive cases in 2018 and 2020, and this has also included hunted animals. A summary of CWD surveillance in Finland is given in Table 3.

\section{The EU programmes 2007-2010 and 2018-2020}

Between 2007 and 2010, an EU-regulated surveillance of CWD was performed in Europe [62]. The results were evaluated by the European Food Safety Authority (EFSA) in 2010, and it was concluded that the presence of CWD could not be excluded [65]. One shortcoming of the surveillance programme that was identified was that sampling had mainly focused on healthy animals [66] and had tested a low number of cervids (600 per country). After detection of CWD in Norway, EFSA was asked to assess the need for surveillance for CWD in Europe. Based on the scientific opinion from EFSA [67] that suggested a surveillance programme with the aim of confirming or excluding the presence of CWD in countries where the disease had not been detected, and estimation of the prevalence and geographical spread, a three-year surveillance programme was initiated through European Commission regulation [68]. This programme covers all EU member states with populations of moose and/or reindeer, i.e., Estonia, Finland, Latvia, Lithuania, Poland, and Sweden. Species included in the surveillance were Eurasian tundra reindeer, Finnish forest reindeer (Rangifer tarandus fennicus), moose, roe deer (Capreolus capreolus), white-tailed deer (Odocoileus virginianus), and red deer. The sampling target was set to 3000 captive cervids and 3000 wild or semidomesticated cervids, but to be adapted based on population size. In addition, sampling should focus on fallen/

Table 3 CWD surveillance and diagnoses in Finland (2006-2020)

\begin{tabular}{|c|c|c|c|c|c|c|c|c|c|}
\hline & $2006-10$ & 2011-16 & 2017 & 2018 & 2019 & 2020 & $2021^{a}$ & Sum & CWD \\
\hline Moose (Alces alces) & 86 & 51 & 48 & $242(\mathbf{1})$ & 162 & $200(\mathbf{1})$ & 29 & 818 & 2 \\
\hline Reindeer (Rangifer t. tarandus) ${ }^{\mathrm{b}}$ & 45 & 29 & 16 & 294 & 616 & 624 & 95 & 1719 & \\
\hline Finnish forest reindeer (Rangifer t. fennicus) ${ }^{c}$ & 3 & 4 & 13 & 14 & 12 & 7 & 8 & 61 & \\
\hline White-tailed deer (Odocoileus virginianus) ${ }^{d}$ & 612 & 27 & 23 & 50 & 131 & 125 & 25 & 993 & \\
\hline Red deer (Cervus elaphus) & & & & & & 1 & & 1 & \\
\hline Fallow deer (Dama dama) & 10 & 3 & 1 & & & & & 14 & \\
\hline Roe deer (Capreolus capreolus) & 23 & 14 & 13 & 63 & 208 & 255 & 47 & 623 & \\
\hline
\end{tabular}

CWD positive diagnosis is given as number in bold in parenthesis and the total number of tested animals and the total number of diagnosed cases are also prenseted in bold in the two rightmost columns of the tables

${ }^{\text {a }}$ April 15th

${ }^{\mathrm{b}}$ All semi-domesticated

$c, d$ Wild. Positive diagnosis of CWD in parentheses 
culled, clinically sick, and road- or predator-killed animals, or hunted or slaughtered cervids which have been declared unfit for human consumption by meat inspection. Brainstem and lymph nodes should be sampled and analysed by one of the rapid tests approved in the regulation [68], and positive results confirmed by WB or immunohistochemistry (IHC). In case of confirmedpositive cases, the sampling should be increased based on a risk assessment. The results of this programme are reported to EFSA by the member states involved and published in annual reports [69]. Although sampling animals of the selected target groups could be challenging due to the necessary logistics when animals die in remote areas [70], EFSA concluded in 2019 [71] that testing higher risk animals is more informative about the disease than testing healthy animals [71]. Funding and political will have had an impact on the number of samples collected in different countries [70].

\section{Outbreak in Norwegian wild reindeer-management and disease features}

In March 2016, a team from the Norwegian Institute for Nature Research observed a diseased reindeer during field operations (collaring) in the Nordfjella wild reindeer population (Fig. 1). It died after a few minutes and was submitted to the Norwegian Veterinary Institute for necropsy. After the diagnosis of this first CWD case, a surveillance programme was launched, resulting in the identification of three additional positive reindeer during the 2016 hunting season.

The Norwegian Food Safety Authority and the Norwegian Environment Agency requested the Norwegian Scientific Committee for Food and Environment for a scientific opinion to address food-safety aspects of CWD and management options concerning the outbreak of contagious CWD among wild reindeer in the Nordfella area. This opinion concluded that eradication of CWD in wild reindeer in Norway, could only be achieved through culling the affected population [72]. Surveillance data prior to, and during, the cull confirmed a low prevalence, and animal-to-animal spread was considered the predominant mode of transmission, rather than via environmental contamination [73]. However, the Nordfjella area is actively used as summer pastures for sheep (around 50,000 per season) and a high number of salt licks for sheep are allocated in the area, several of which were also used by wild reindeer. Environmental build-up of CWD infectivity at such "hot spots" was therefore considered a high risk [73]. Importantly, despite neighbouring populations of semi-domesticated reindeer to the north, wild reindeer to the south, and sympatric red deer and moose, the affected population was considered to be semi-isolated from these by roads and railway. Considering all these aspects, culling of all reindeer in the affected area was advised (Fig. 2). A fallow period of a least five years was recommended before reintroduction of reindeer to the area.

Data from North America have shown that mule deer [74] and white-tail deer [75] males are more likely than females to test positive for CWD. The results from $>2000$ culled Norwegian wild reindeer revealed a similar distribution [76]. The chance of positive CWD-diagnosis for adult males was about 2.7 times $(\mathrm{P}<0.05)$ the risk of females. This knowledge, together with other disease characteristics, were used when modelling was refined to assist hunting and management strategies [77, 78]. Norwegian wild reindeer and other wild cervid populations are regulated by recreational hunting, making this important for surveillance and disease management [79].

Genetic variation in PRNP, the gene encoding cellular PrP, has long been recognized as an important factor in prion-disease modulation in both animals and humans. Prior to detection of CWD in Europe, characterization of PRNP genetic variation among European cervids was limited to studies of non-affected populations [80, 81] and later, [82, 83] studies of genetic variation across endemic species. Culling of the Norwegian wild-reindeer population affected with CWD [84] allowed correlation of PRNP variation with diagnosis of CWD [85]. Five variants (alleles) of the PRNP gene (A-E) were identified in Norwegian reindeer, combining into 14 PRNP genotypes. Two of the alleles, A, thought to be the archetypic gene variant in reindeer, and $C$ (octapeptide deletion) were both strongly overrepresented $(\mathrm{P}<0.001$ for animals carrying two copies of the $\mathrm{A}$ or $\mathrm{C}$ allele) among the CWD animals, whereas the opposite was the case for animals carrying the B allele in which serine in position 225 is substituted with tyrosine. Despite small numbers, the authors concluded that the PRNP genetic influence on susceptibility of reindeer to the CWD strain observed in Norwegian reindeer is substantial [85]. These data are valuable for further PRNP genetic susceptibilityprofiling of non-affected wild and semi-domesticated reindeer populations.

\section{CWD in Norwegian reindeer}

The first case of CWD in reindeer was detected by testing for the presence of $\mathrm{PrP}^{\mathrm{Sc}}$ on medulla oblongata at the level of the obex with an enzyme-linked immunosorbent assay (TeSeE SAP ELISA CWD, Bio-Rad) (Fig. 3a, b). As a confirmatory method, WB (TeSeE, Bio-Rad) was applied. Three proteinase K-resistant bands with estimated molecular mass between 17 and $29 \mathrm{kDa}$ were obtained from the medulla sample. This three-banded pattern was indistinguishable from that of a North 


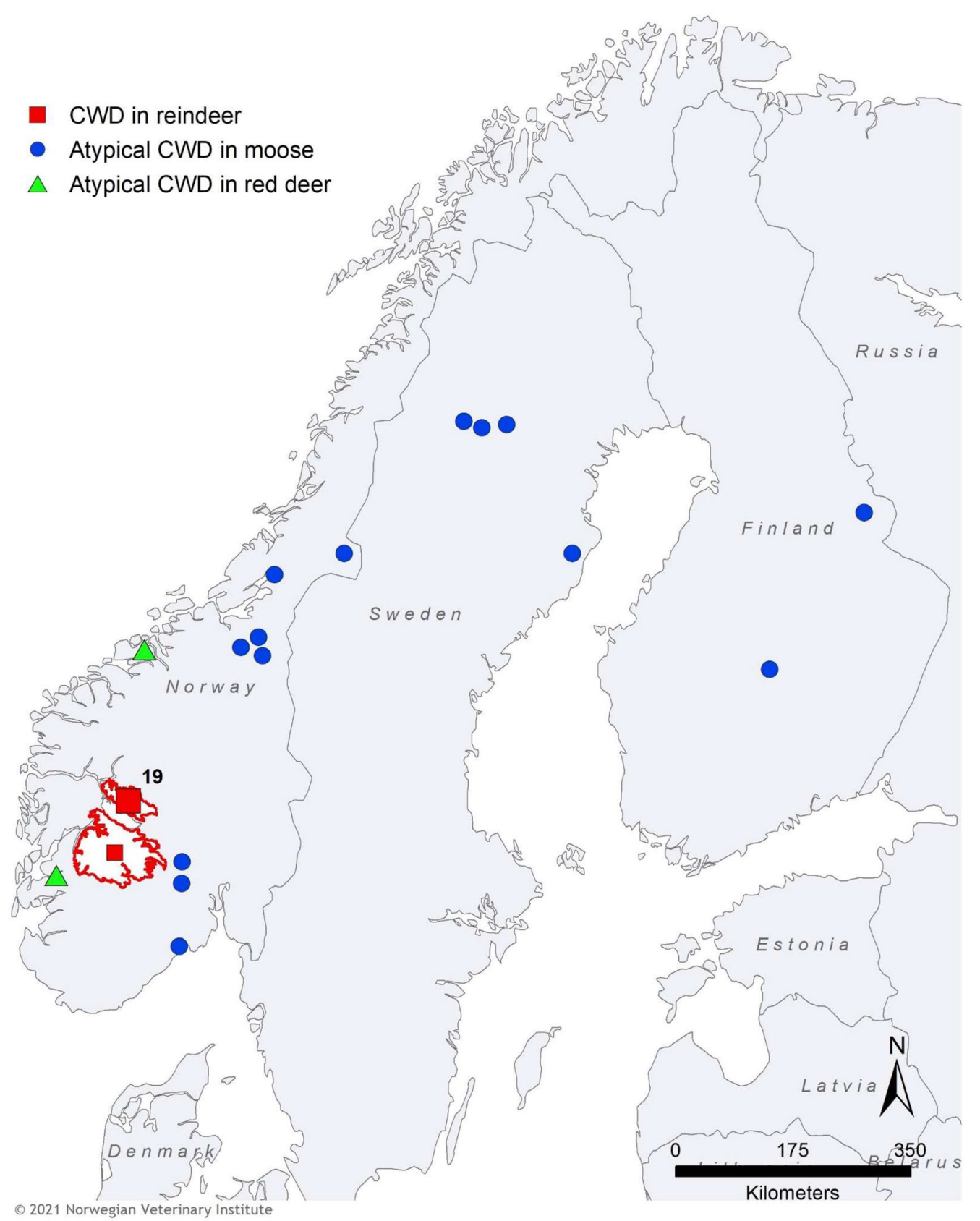

Fig. 1 Distribution of CWD in reindeer, red deer, and moose in Fennoscandia as per April 2021. The outbreak of CWD among reindeer in Nordfjella, with a total of 19 cases, is indicated with a red square. The subsequent case diagnosed in a reindeer in 2020 is indicated with a smaller red square. The Nordfjella and Hardangervidda reindeer areas are marked with a red line. Atypical cases of CWD in moose are shown with blue circles and the two cases in red deer with green triangles

American CWD isolate [54], thus providing no hints of the strain differences that would later appear from transmission experiments.

Visualisation by $\mathrm{IHC}$ of $\operatorname{PrP}^{\mathrm{Sc}}$ deposits in tissues using monoclonal antibody $(\mathrm{mAb})$ immunolabelling will hereafter be referred to as "staining". The $\operatorname{PrP}^{\mathrm{Sc}}$ distribution in this animal resembled what has been described in North American CWD cases, with heavier staining in the ventral brain areas, as extensive perineuronal, perivascular, granular or plaque-like staining [54]. In the investigated lymph nodes, $\operatorname{PrP}^{\mathrm{Sc}}$ staining was observed in the lymphoid follicles [54]. 


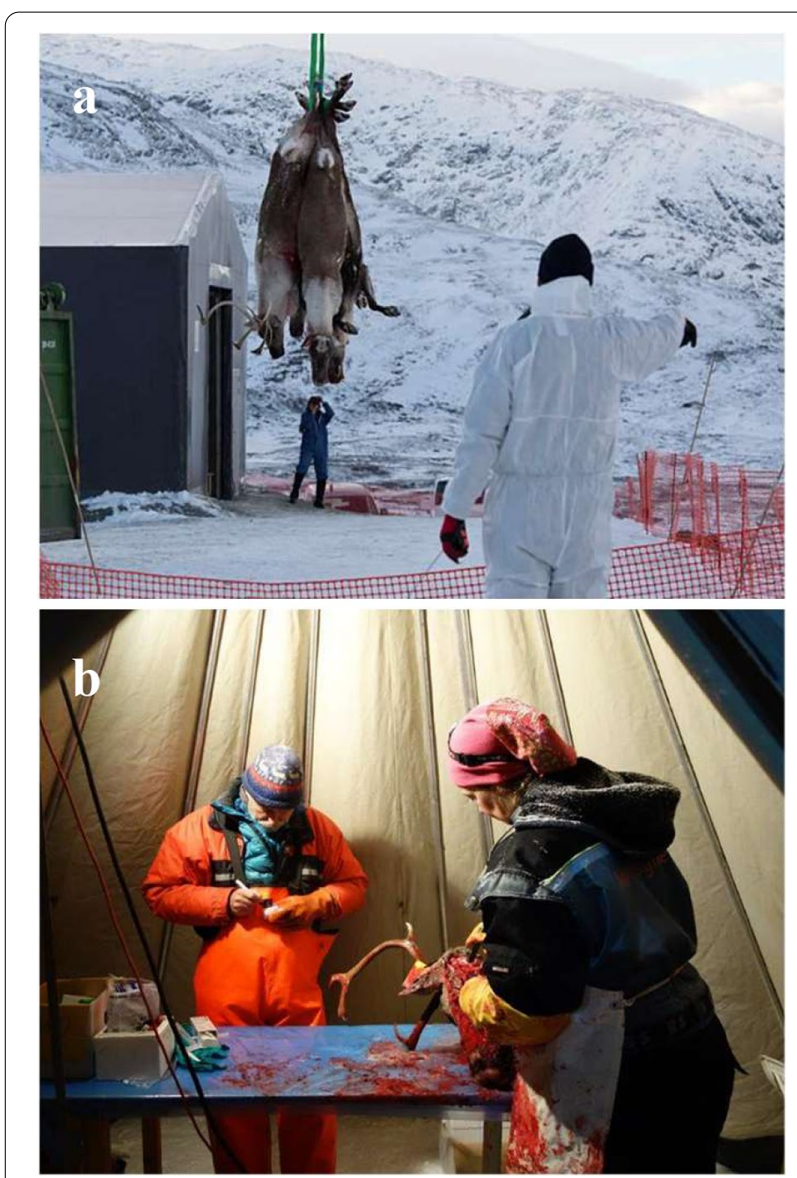

Fig. 2 Images from the cull of the reindeer population in Nordfiella. Shot animals were transported with snowmobiles or helicopter to sites for sampling. All carcasses were destroyed with incineration after sampling

\section{CWD in European moose}

For CWD screening of moose, ELISA-based rapid tests, TeSeE SAP ELISA CWD (Bio-Rad) and/or IDEXX HerdCheck ELISA were applied to samples from medulla oblongata at the level of the obex, and retropharyngeal lymph nodes, or other lymphoid tissues, when available. In Norway, the four first CWD cases were identified with the Bio-Rad test and the four last with the IDEXX test. All four cases in Sweden were identified with the Bio-Rad test, while the two cases in Finland were identified with the IDEXX test. Lymphoid tissue was available from all the positive moose, except one Norwegian case. $\operatorname{PrP}^{\mathrm{Sc}}$ was not detected in any of the lymphoid tissues tested in any of the moose [56, 71]. Positive ELISA results on obex tissues were confirmed by WB (TeSeE western blot Bio-Rad).

IHC characterization of $\mathrm{PrP}^{\mathrm{Sc}}$ accumulation was published for three Norwegian CWD-positive moose [56] and the following paragraph recapitulates the main findings in that report (Fig. 3c, d). Samples from a CWDpositive reindeer from Norway were included for comparison. It appeared that $\mathrm{PrP}^{\mathrm{Sc}}$ distribution was distinct from that seen in North American CWD cases. The differences can be subtle, as illustrated by use of anti-PrP mAbs raised against different parts of $\operatorname{PrP}$ as well as examination of several brain regions and lymphoid tissues. IHC was performed with a panel of five anti-PrP mAbs raised against different parts of PrP. All three moose showed $\mathrm{PrP}^{\mathrm{Sc}}$ staining in the brain, with the intensity, patterns, and distribution of the staining differing among the animals. $\mathrm{PrP}^{\mathrm{Sc}}$ was predominantly observed as intraneuronal aggregates and, to a lesser degree, as intra-astrocytic and intra-microglial staining in the cerebral cortices and the olfactory bulb. In the obex area, stained neurons were observed in all nuclei, but unlike observations from most CWD cases, the dorsal motor nucleus of the vagal nerve (DMNV) was not strongly stained. The cerebellum was positive in one of the moose, while $\mathrm{PrP}^{\mathrm{Sc}}$ staining was observed in all other brain areas in all three animals. Importantly $\operatorname{PrP}^{\mathrm{Sc}}$ staining was not detected intra-neuronally with the more N-terminal mAbs, in any of the three moose [56]. Furthermore, $\operatorname{PrP}^{\mathrm{Sc}}$ was not detected in any of the lymphoid tissues of the moose. Overall, these features were different from those observed in reindeer, where $\operatorname{PrP}^{\mathrm{Sc}}$ distribution was similar to that described in North American cervids with CWD [86-88] and in which the panel of all five mAbs revealed the same $\operatorname{PrP}^{\mathrm{Sc}}$ accumulation and distribution [56].

The variability of IHC staining properties and WB band patterns among CWD cases in moose is still under investigation and the scientific significance of these observations also remains to be clarified. Preliminary data from IHC characterization of the brain of CWD-positive moose in Sweden and from additional moose in Norway have confirmed a predominance of intraneuronal $\mathrm{PrP}^{\mathrm{Sc}}$ accumulation (Unpublished observations).

In summary, IHC with the panel of mAbs demonstrated differences in $\operatorname{PrP}^{\mathrm{Sc}}$ staining between moose and reindeer (Fig. 3e, f). In the first three Norwegian CWD moose analysed, the lack of staining with mAbs that bind to the N-terminal tail of PrP indicate that this part of the protein, in these cases, had been removed by endogenous proteases. The brain distribution and patterns of $\mathrm{PrP}^{\mathrm{Sc}}$ accumulation in the brain and in the lymphoid system differed between moose and reindeer and, importantly, some differences were observed among the three moose.

Detailed WB analysis of proteinase $\mathrm{K}$ resistant PrP ${ }^{\text {res }}$ fragments of the three first Norwegian cases in moose revealed a different banding pattern than that observed in Norwegian reindeer or for Canadian isolates in different cervid species [56]. The $\mathrm{PrP}^{\text {res }}$ from the Norwegian 

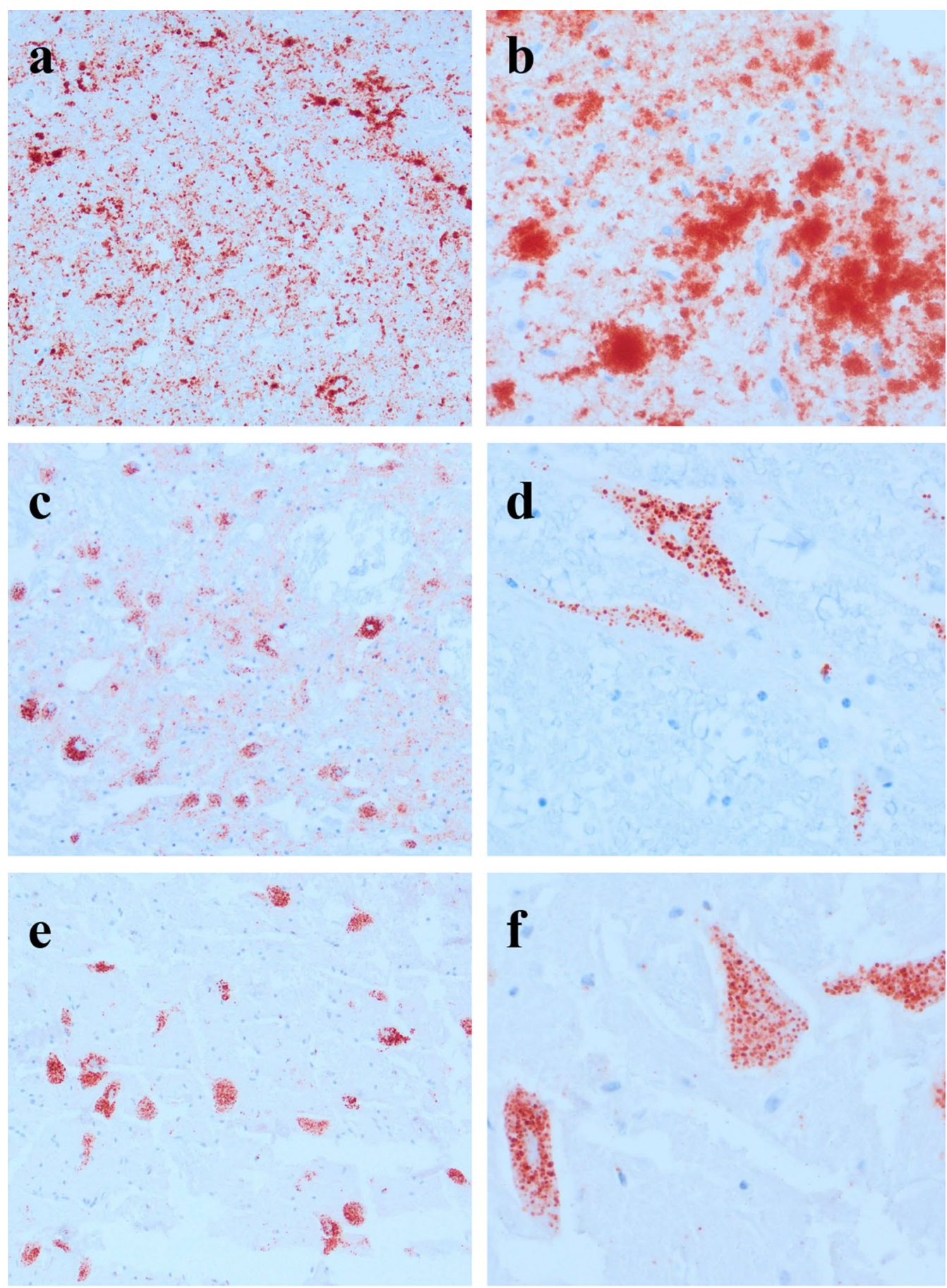

Fig. 3 Immunohistochemical labelling of $\mathrm{Pr}^{\mathrm{SC}}$ in the brain of reindeer and moose diagnosed with CWD. a, b Reindeer, medulla oblongata, strong, extracellular thin and coarse granular, coalescing and plaque-like PrPSc deposition (SAF84 mAb). c, d Atypical CWD in a Norwegian moose, medulla oblongata, predominance of intraneuronal PrPSC deposition ( $L 42 \mathrm{mAb}$ ). e, f Atypical CWD in a Swedish moose, thalamus, intraneuronal PrPSc deposition (SAF84 mAb)

moose had a lower molecular weight, explained by the removal of larger $\mathrm{N}$-terminal parts of the protein by proteinase $\mathrm{K}$, as confirmed by the partial loss of the 12B2 epitope. This includes residues 93-WGQGG-97 in cervid PrP (Fig. 4A, 9A2 and 12B2 blot). Although the 12B2 epitope was mainly absent for all moose, the amount of 
$\mathrm{PrP}^{\text {res }}$ still detectable by $12 \mathrm{~B} 2$ was variable among the first three moose, suggesting variability in the $\mathrm{N}$-terminal proteinase K-cleavage sites. This variability has also been observed among new cases in moose that are currently under investigation.

Furthermore, by using more C-terminal mAbs, such as SAF84 and L42 (Fig. 4a), it was found that moose PrPres gave an unusual and complex WB pattern that could be explained by the presence and overlapping of additional fragments (Fig. 4). All moose isolates showed the presence of a C-terminal fragment of $\approx 13 \mathrm{kDa}$ (CTF13) detected by SAF84 (Fig. 4). Importantly, the PrP ${ }^{\text {res }}$ pattern varied slightly among the Norwegian moose cases. Indeed, an additional C-terminal fragment of $16 \mathrm{kDa}$ (CTF16) was detected in moose-2 and moose-3 (Fig. 4a, SAF84 and L42 blots). Another fragment of $10 \mathrm{kDa}$, cleaved by proteinase $\mathrm{K}$ at both $\mathrm{N}$ and $\mathrm{C}$ termini of $\operatorname{PrP}^{\mathrm{Sc}}$, was detected in moose- 1 and moose- 3 [56]. The PrPres banding patterns derived from Norwegian moose cases were compared with $\mathrm{PrP}^{\text {res }}$ features from a Canadian moose case of CWD. In contrast to the Norwegian cases, the Canadian case had $\operatorname{PrP}^{\text {res }}$ patterns that were indistinguishable from those of other CWD isolates from Canadian cervids. In addition to these molecular observations, cases of CWD in North American cervids with detectable $\mathrm{PrP}^{\mathrm{Sc}}$ in lymphoid tissues have been reported, which contrasts with findings from CWD isolates from Fennoscandian moose $[38,89]$. This suggests that the atypical $\mathrm{PrP}^{\mathrm{Sc}}$ type observed in Norwegian moose could not simply reflect a factor related to host species.

In order to investigate the possible relationships between CWD in moose and TSEs in other animal

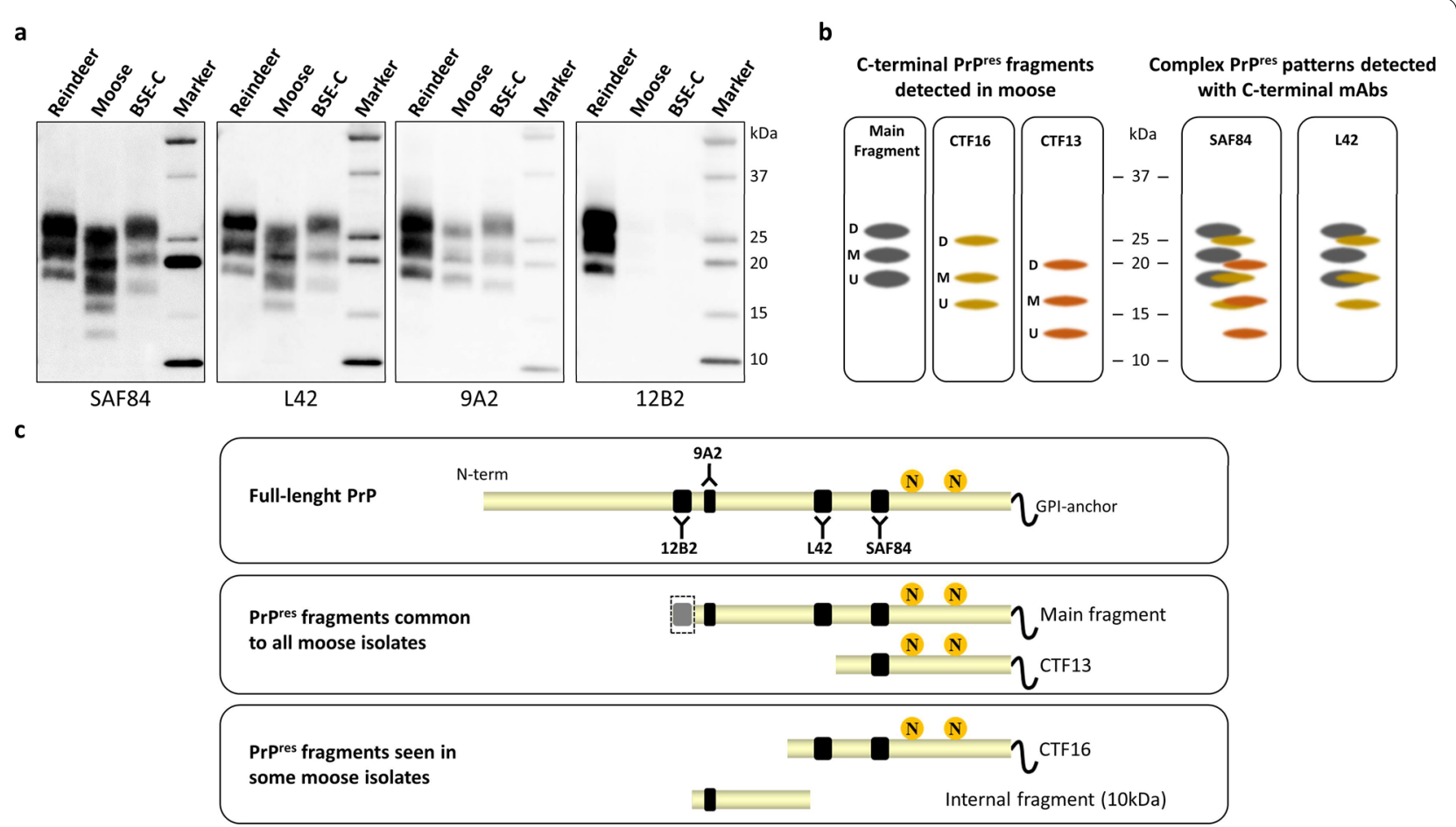

Fig. 4 Western blots analysis and interpretation of protease K-treated PrPS (PrPres) from Norwegian reindeer and moose diagnosed with CWD, and from a bovine with classical BSE (BSE-C). a Replica blots analysed with mAbs recognizing different epitopes on PrP, as indicated below each blot. The epitopes of the mAbs are shown in c The positions of molecular weight (MW) markers are indicated on the right of the blots (in kilodaltons). Reindeer CWD is detected by the N-terminal mAb 12B2, while moose CWD and BSE-C are not. With mAb 9A2 all samples show a three-banding pattern representing di-, mono- and un-glycosylated Prpres, whose molecular weight is lower in moose than in reindeer ("Main fragment" in $\mathbf{b}$ and c). In contrast, mAbs directed to more C-terminal epitopes, L42 and SAF84, recognize additional low molecular weight Prpres fragments at $\sim 13$ and $16 \mathrm{kDa}$, detected in moose (referred to as CTF16 and CTF13 in $\mathbf{b}$ and c), which are glycosylated too (51). $\mathbf{b}$ Cartoons representing Prpres fragments detected in moose with CWD. Main, CTF16, CTF13 fragments are represented separately, with their di-glycosylayed (D), mono-glycosylated (M) and un-glycosylated $(U)$ bands. On the right, the cartoons representing the different PrPres fragments detected in moose PrP ${ }^{S c}$ are joined to show the interpretation of the complex WB patterns observed with SAF84 and L42. The position of the cartoons is in accord with the position of the bands in the blots shown in a. c. Cartoons representing full-length PrP and the different PrPres fragments detected in moose, with the position of the epitopes recognised by the mAbs used in a (ovine PrP numbering: SAF84, aa 167-173; L42, aa 148-153; 9A2, aa 99-101; 12B2, aa 93-97). Note that the $12 \mathrm{~B} 2$ epitope is shaded in the main PrPres fragment to indicate the variability in the $\mathrm{N}$-terminal Proteinase K-cleavage observed in moose with CWD. Yellow circles labelled with " $\mathrm{N}$ " represent the position of N-linked sugars. The GPI anchor is represented at the C-terminus 
species, moose PrP ${ }^{\text {res }}$ fragments were also compared with $\mathrm{PrP}^{\mathrm{res}}$ derived from European sheep and cattle [56]. In these studies, moose $\mathrm{PrP}^{\mathrm{res}}$ was clearly distinguishable from the most common animal TSEs, such as classical scrapie and atypical scrapie in small ruminants, as well as from classical and atypical BSE in bovines (see, for example, Fig. 4a). Although some similarities were observed with a rare form of scrapie, referred to as $\mathrm{CH} 1641$-like, cases of CH1641 scrapie have not yet been detected in Norway [56]. The CH1641 scrapie isolate was derived from a natural case of scrapie in a Cheviot sheep [90] and has attracted interest because of shared molecular features with experimental BSE in sheep [91]. A few natural isolates have been described in sheep in Europe, showing molecular and biological similarities to $\mathrm{CH} 1641$ [92-94], and these were named $\mathrm{CH} 1641$-like. All cases of $\mathrm{CH} 1641$ scrapie reported in EU so far were detected during the surveillance activity on animal TSEs in Europe and no such cases have been recorded in Fennoscandia.

\section{Confirmed cases in moose-management and disease features}

After detection of positive cases in moose, surveillance in areas surrounding the cases was launched in Norway, Finland, and Sweden. The aim was to assess disease occurrence as a basis for control or management options. Moose often live alone and have a complex movement behaviour, with some animals remaining close to their home range, others dispersing, and some travelling larger distances (150-200 km) in a migratory pattern that is sometimes seasonal [95]. As surveillance prior to the detection of positive cases has been very limited, the prevalence and the geographical extension of the disease in those areas where the cases were detected was largely unknown.

As data from surveillance and characterisation of the isolates accumulated, it became clear that the cases had features in common that were distinct from the findings in wild reindeer and from North American cases. The most prominent of these features were the old age of the animals and particular distribution of detectable prions. All cases in moose in Fennoscandia detected so far have been in moose above 10 years of age (Table 4), with prions detected in brain, but samples from lymph nodes being negative. This could suggest that these cases may be of spontaneous, rather than contagious origin $[56,72]$. The Norwegian Scientific Committee for Food and Environment evaluated the emerging data in conjunction with established knowledge on moose ecology and concluded that a culling strategy would not be efficient in controlling the disease. However, spatially targeted harvesting, based on epidemiological observations, was also considered a viable option. The majority of the
Table 4 Sex and age-distribution of moose diagnosed with CWD in Fennoscandia

\begin{tabular}{|c|c|c|c|}
\hline \multirow{2}{*}{ 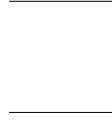 } & \multicolumn{2}{|l|}{ Sex } & \multirow[t]{2}{*}{ Age, years } \\
\hline & Male & Female & \\
\hline Norway & 1 & 7 & $12,13,13,13,14,15,17,20$ \\
\hline Sweden & & 4 & $10,14,16,16$ \\
\hline Finland & & 2 & 15,18 \\
\hline Sum & 1 & 13 & Mean age: 14.7 \\
\hline
\end{tabular}

moose are hunted at young age, especially males, resulting in a skewed age structure in the population with few males reaching above 10 years of age, which may be a reason for cases being detected predominantly in female moose [96]. None of the countries that have identified the disease in moose have used a culling strategy so far, and are still undertaking intensified sampling, epidemiological investigations, and further characterisation of the isolates.

\section{CWD cases in Norwegian red deer}

Two cases of CWD have been observed in wild red deer $[97,98]$. The first case was an asymptomatic 16-year-old female shot grazing in farmland during regular hunting in 2017. CWD was diagnosed as described for the moose and reindeer cases. The obex was shown to be positive by ELISA, but all lymph nodes were negative. IHC of obex, lymph nodes, and tonsils was conducted using three different mAbs [54]. $\operatorname{PrP}^{\mathrm{Sc}}$ deposition was demonstrated in the obex area with two of the mAbs, both showing coarse granular accumulation in the neuropil as well as perineuronal, intraneuronal, and linear staining in several nuclei and axonal tracts. The mAb raised against the $\mathrm{N}$-terminal part of the PrP showed weaker labelling and no intraneuronal deposition. Staining was not shown in any of the lymphoid tissues tested [98]. In September 2021, a further case of CWD in red deer was reported from Norway [97]. Still under investigation, diagnostic data suggest that this case is similar to the first case described above i.e., an atypical form of the disease. The findings from these cases differ from those shown in red deer experimentally infected by the oral route with isolates from North American CWD, and which resulted in a disseminated prion disease with $\mathrm{PrP}^{\mathrm{Sc}}$ accumulation in the brain, lymphoreticular and other peripheral tissues [99]. CWD has also been reported in a young captive red deer in North America, which also showed $\mathrm{PrP}^{\mathrm{Sc}}$ in both brain and lymphoid tissues [100]. The analysis of the $\mathrm{PrP}^{\mathrm{Sc}}$ features of the two Norwegian red deer cases showed an unexpected $\mathrm{PrP}^{\mathrm{res}}$ pattern, with some similarities to that seen in BSE in cattle. Bioassays are currently ongoing to determine the characteristics of the strain. 
Transmission experiments and strain heterogeneity Characterising the properties of the emerging CWD prion strains in Europe is of fundamental importance. Understanding their biological properties and behaviour is essential for designing appropriate control and/or eradication measures and for informing policy. Additionally, strain typing is necessary to provide information on the origin and relatedness of the newly detected CWD cases and for determining the potential risks to animals and human health.

A strain typing study involving transmission to bank voles, compared and characterised CWD prion isolates from various cervid species in Canada (elk, white tailed deer and moose) and Norway (reindeer and moose) [55]. In primary transmission, CWD prion isolates from Canada transmitted efficiently to bank voles, in keeping with previous data obtained using CWD isolates from the USA [101]. Despite the similarity of the molecular and pathological phenotypes with North American CWD cases, the transmission of CWD from Norwegian reindeer was very inefficient, suggesting the involvement of a distinct prion strain. Finally, moose CWD isolates from Norway transmitted efficiently, but with longer survival time than North American CWD isolates. These three different transmission patterns were associated with different neuropathological and $\mathrm{PrP}^{\mathrm{Sc}}$ characteristics in bank voles. Of note is that some of the peculiar features observed in Norwegian moose [56] were preserved after transmission to bank voles, such as cortical involvement, the presence of abundant intraneuronal $\mathrm{PrP}^{\mathrm{Sc}}$ deposits, and the complex pattern of proteinase $\mathrm{K}$ resistant $\operatorname{PrP}^{\mathrm{Sc}}$ fragments observed by WB. $\mathrm{PrP}^{\mathrm{Sc}}$ typing with mAbs directed to different PrP epitopes showed the presence of $13 \mathrm{kDa}$ PrP $^{\text {res }}$ fragments (CTF13) in bank voles infected with Norwegian moose CWD isolates, but not in those infected with Norwegian reindeer or North American CWD sources [55]. These findings suggest that these neuropathological and biochemical features could be potentially considered as discriminative phenotypes for Norwegian moose CWD.

Adaptation of the CWD isolates in bank voles by further sub-passaging, led to the isolation of four different bank vole-adapted CWD strains: one from the Canadian cases, which was indistinguishable from the vole-adapted strain previously isolated from several US CWD isolates [101], one from Norwegian reindeer, and two from Norwegian moose cases (derived from moose-1 and moose2) [55]. While both moose-derived CWD strains were characterised by the presence of CTF13 PrP ${ }^{\text {res }}$, they were distinguishable by their main PrP $^{\text {res }}$ fragments, showing that the slightly different $\mathrm{PrP}^{\text {res }}$ pattern observed in CWD isolates from moose- 1 and moose- 2 was preserved after transmission and adaptation in bank voles and was associated with slightly different neuropathological phenotypes. Finally, it was noticed that the adaptation of the moose-2 CWD strain was slower than with the other CWD isolates, possibly suggesting an ongoing competition between different strain components during the adaptation in bank voles. Such interplay between co-existing prion strains is a known phenomenon, also observed for CWD $[102,103]$. In keeping with the complex and variable $\mathrm{PrP}^{\mathrm{res}} \mathrm{WB}$ patterns observed in moose CWD cases [56], this finding might suggest a scenario in which different strains could co-exist in moose and can be selectively propagated during experimental transmission in a heterologous species, such as bank voles. The ongoing molecular and biological characterization of moose CWD cases detected in Fennoscandia will help to clarify this issue.

In summary, the strain typing studies in bank voles demonstrated that the CWD prions found in cervids in Norway are distinct from those found in North America. This suggests that the CWD emergence in Norway is probably not linked to recent introduction from North America. Furthermore, CWD in Norwegian cervids was caused by four different strains, two in moose, one in reindeer and one in red deer. Strain typing of the red deer isolate is under investigation but analysis of the $\mathrm{PrP}^{\mathrm{Sc}}$ glycoprofile strongly indicates that this is a unique strain. These results suggest that interspecies circulation of CWD strains between moose and reindeer in Norway have not occurred, and this is supported by data obtained so far from CWD surveillance in Norway. However, only a subset of CWD isolates from reindeer and moose has been studied so far, and studies of additional CWD cases, detected in moose in Norway, Finland, and Sweden, as well as several reindeer in Norway are ongoing. It is important to characterize CWD strain variations in moose from Fennoscandia, to assess the potential relationships between the diseases in different cervid species, and, importantly, to assess the zoonotic potential of emergent or newly recognised CWD in Europe.

\section{Perspectives}

The discovery of CWD in Norway in 2016 was surprising because previous wildlife disease monitoring and CWD surveillance in Norway and other European countries, even if limited, had not indicated that this disease occurred in Europe. Five years later, the situation has dramatically changed. CWD has been diagnosed in moose in Norway, Sweden, and Finland, in a novel, potentially sporadic, form. The epidemiology, age of the animals, prion strain features, and tissue distribution differ from CWD in its typical contagious form. This, and the diagnosis of yet-another, unique CWD type in a red deer in Norway, 
shows that CWD no longer is a relatively homogenous disease entity, but covers a family of cervid prion diseases caused by multiple prion strains of unknown origin. Moreover, strain variation seems to be present among moose CWD cases encoding identical PRNP genotypes. The root-cause of this strain pleiotropy is incompletely understood.

Following the recent developments, with apparent expansion of the CWD family, disease classifications should be modified to reflect this and there should be appropriate support for governments, stakeholders, and the public in addressing these emerging challenges. This would be similar to the approaches used with atypical BSE (BASE/L-BSE and H-BSE) in cattle and Nor98/ atypical scrapie in sheep and goats. In these cases, intensive surveillance and epidemiological analyses contributed to recognition of different epidemiological patterns followed by targeted control strategies [68].

Sporadic prion diseases would be expected to occur wherever the relevant age-segment of the species is present. Moreover, members of the Cervidae family encode prion proteins with shared structural features that appear to allow inter-cervid species prion-disease transmission. Given the global distribution of cervids, together with the probability of spontaneous cases of CWD, it can be speculated that CWD is present in cervid populations outside North America and Fennoscandia. Current evidence from CWD surveillance in Norway and previous experience from the large-scale testing necessary for detection of Nor98/atypical scrapie in sheep [24], suggest that persistent surveillance is required to address this.

Primary passage of transmission experiments into humanized mice (transgenic mice expressing the human PRNP gene) with isolates from three of the Norwegian cases (one moose, one reindeer, and one red deer) were reassuringly negative, suggesting a strong transmission barrier to humans, as previously reported for North American CWD [104]. However, further investigations are ongoing, with several Norwegian CWD isolates and different lines of humanized mice.

\section{Conclusions}

The 2018 cull of the Nordfjella wild reindeer removed the only known European cervid population with contagious CWD. A further case with similar disease characteristics was in 2020 diagnosed in a neighbouring management area, questioning the prospects of CWD eradication in wild reindeer in Western Europe. There is no apparent link between CWD in Norwegian reindeer and the cases in Norwegian moose or the two cases in Norwegian red deer. However, investigations of disease characteristics have revealed interesting similarities between the 14 cases of CWD in moose diagnosed in Fennoscandia and atypical prion disease in cattle and small ruminants, with sporadic occurrence in old animals (i.e., an atypical form of CWD). Several lines of evidence point to prion strain variation among the moose cases. Further investigations aiming at clarifying the molecular basis for, and the scientific and epidemiological significance of these observations are ongoing. The origin of CWD in Europe is unknown, but the newly characterised European strains differ significantly from North American strains, perhaps arguing in favour of an in-situ origin rather than recent trans-Atlantic transfer.

\section{Acknowledgements \\ The authors wish to thank Lucy Robertson for critically reading the manu- script. Attila Tarpai for providing the map in Figure 1. The photos in Figure 2 are reproduced with permission from the Norwegian Food Safety Authorities. Department of Biohazard and Pathology, especially Linh Tran, at the NVI is acknowledged for the CWD analyses.}

\section{Authors' contributions}

MAT was invited by AVS to write a review on the topic and has coordinated the writing process. MAT drafted the Abstract, Background, Perspectives and Conclusions sections. JV and MAT drafted the part on Norwegian CWD surveillance and reindeer CWD. MN drafted the text on CWD surveillance in Sweden and the EU. DGW drafted the sections on diagnostics, pathology, $I H C$ and transmission studies. RN and LP drafted the text on WB and transmission studies. SLK and MH drafted the text on CWD surveillance in Finland. SLB drafted the sections on diagnostics, pathology, IHC and WB. All authors have actively participated in revising and discussing the entire text. All authors read and approved the final manuscript.

\section{Authors' information}

MAT is a veterinarian and professor in Biochemistry at the Norwegian University of Life Sciences. He has performed research in the field of prion diseases since 1996, with focus on sheep scrapie and studies of the physiological functions of the prion protein. DGW is a veterinary pathologist specialized on wildlife diseases, she has conducted research on and diagnostics of animal prion diseases. JV, veterinarian, and senior researcher in wildlife health at NVI and CWD-coordinator and head of the CWD disease programme at NVI. MN, veterinary epidemiologist, has worked with TSEs since 1999, mainly surveillance, and have done research on epidemiology of Nor98/atypical scrapie. LP (DVM, PhD) is a researcher at the Istituto Superiore di Sanità, Italy. Since 2008 she has investigated human and animal prion strains by biochemical and biological assays. She is responsible for biochemical strain characterization of animal TSEs for NRL in Italy and responsible for discriminatory testing and biochemical discrimination of prion strains for European Reference Laboratory for TSEs. SLK is a veterinarian, Specialist in Veterinary Medicine, Infectious Diseases. She has worked since 2002 at Finnish Food Authority virology unit, in the field of prion diseases. She is responsible for diagnostics of animal prion diseases. MH is Senior Researcher (PhD) at the Finnish Food Authority Virology unit and has worked with TSEs since 2002, mainly in diagnostics and sheep PRNP genotyping. RN is a veterinarian and research scientist in the Emerging Zoonosis Unit at the Istituto Superiore di Sanità in Rome, Italy. He is responsible for the biological characterization of prion strains in the European Reference Laboratory for TSEs. His primary research interests include prion strains and the zoonotic potential of animal prion diseases. SLB is Senior Researcher at the NVI in Norway. She is leading the Norwegian Reference Laboratory for TSE in animals and is the expert for the OIE Reference Laboratory for CWD. She is working with diagnostic and research on prion diseases since 1997 , especially with characterization of prion strains, Nor98 / atypical scrapie in sheep and since 2016 on CWD.

Funding

Not applicable.

Availability of data and materials Not applicable. 


\section{Declarations}

Ethics approval and consent to participate Not applicable.

\section{Consent for publication}

Not applicable.

\section{Competing interests}

The authors declare that they have no competing interests.

\section{Author details}

${ }^{1}$ Department of Preclinical Sciences and Pathology, Faculty of Veterinary Medicine, Norwegian University of Life Sciences, Post Box 5003, Ås, Norway ${ }^{2}$ National Veterinary Institute (SVA), 75189 Uppsala, Sweden. ${ }^{3}$ Department of Biomedical Sciences and Veterinary Public Health, Swedish University of Agricultural Sciences (SLU), Box 7028, 75007 Uppsala, Sweden. ${ }^{4}$ Norwegian Veterinary Institute, Post Box 64, 1431 Ås, Norway. ${ }^{5}$ Finnish Food Authority, Virology Unit, 00790 Helsinki, Finland. ${ }^{6}$ Department of Food Safety, Nutrition and Veterinary Public Health, Istituto Superiore Di Sanità, 00161 Rome, Italy.

Received: 10 May 2021 Accepted: 30 September 2021

Published online: 25 November 2021

\section{References}

1. Prusiner SB, Scott MR, DeArmond SJ, Cohen FE. Prion protein biology. Cell. 1998;93:337-48.

2. Silveira JR, Raymond GJ, Hughson AG, Race RE, Sim VL, Hayes SF, et al. The most infectious prion protein particles. Nature. 2005;437:257-61.

3. Prusiner SB. Prions. Proc Natl Acad Sci U S A. 1998;95:13363-83.

4. Brandner S, Raeber A, Sailer A, Blattler T, Fischer M, Weissmann C, et al. Normal host prion protein (PrPC) is required for scrapie spread within the central nervous system. Proc Natl Acad Sci U S A. 1996;93:13148-51.

5. Bueler H, Aguzzi A, Sailer A, Greiner RA, Autenried P, Aguet M, et al. Mice devoid of PrP are resistant to scrapie. Cell. 1993;73:1339-47.

6. Stahl N, Prusiner SB. Prions and prion proteins. FASEB J. 1991:5:2799-807.

7. Salvesen O, Espenes A, Reiten MR, Vuong TT, Malachin G, Tran L, et al. Goats naturally devoid of $\operatorname{PrP}(C)$ are resistant to scrapie. Vet Res. 2020;51:1.

8. Bremer J, Baumann F, Tiberi C, Wessig C, Fischer H, Schwarz P, et al. Axonal prion protein is required for peripheral myelin maintenance. Nat Neurosci. 2010;13:310-8.

9. Skedsmo FS, Malachin G, Vage DI, Hammervold MM, Salvesen O, Ersdal $C$, et al. Demyelinating polyneuropathy in goats lacking prion protein. FASEB J. 2020:34:2359-75.

10. Prusiner SB, Hsiao KK. Human prion diseases. Ann Neurol. 1994;35:385-95.

11. Schoene WC, Masters CL, Gibbs CJ Jr, Gajdusek DC, Tyler HR, Moore FD, et al. Transmissible spongiform encephalopathy (Creutzfeldt-Jakob disease) Atypical clinical and pathological findings. Arch Neurol. 1981;38:473-7.

12. Schneider K, Fangerau H, Michaelsen B, Raab WH. The early history of the transmissible spongiform encephalopathies exemplified by scrapie. Brain Res Bull. 2008;77:343-55.

13. Williams ES. Chronic wasting disease. Vet Pathol. 2005;42:530-49.

14. Williams ES, Young S. Spongiform encephalopathies in Cervidae. Rev Sci Tech. 1992;11:551-67.

15. Babelhadj B, Di Bari MA, Pirisinu L, Chiappini B, Gaouar SBS, Riccardi $\mathrm{G}$, et al. Prion disease in dromedary camels. Algeria Emerg Infect Dis. 2018:24:1029-36.

16. Henderson DM, Denkers ND, Hoover CE, McNulty EE, Cooper SK, Bracchi LA, et al. Progression of chronic wasting disease in white-tailed deer analyzed by serial biopsy RT-QuIC and immunohistochemistry. PLoS ONE. 2020;15:e0228327.

17. John TR, Schatzl HM, Gilch S. Early detection of chronic wasting disease prions in urine of pre-symptomatic deer by real-time quaking-induced conversion assay. Prion. 2013;7:253-8.
18. Wolfe LL, Spraker TR, Gonzalez L, Dagleish MP, Sirochman TM, Brown JC, et al. PrPCWD in rectal lymphoid tissue of deer (Odocoileus spp.). J Gen Virol. 2007:88:2078-82.

19. Heggebo R, Press CM, Gunnes G, Ulvund MJ, Tranulis MA, Lsverk T. Detection of PrPSc in lymphoid tissues of lambs experimentally exposed to the scrapie agent. J Comp Pathol. 2003;128:172-81.

20. Mabbott NA, Bruce ME. Follicular dendritic cells as targets for intervention in transmissible spongiform encephalopathies. Semin Immunol. 2002:14:285-93.

21. van Keulen $L$, Schreuder BE, Meloen RH, Mooij-Harkes G, Vromans ME, Langeveld JP. Immunohistochemical detection of prion protein in lymphoid tissues of sheep with natural scrapie. J Clin Microbiol. 1996;34:1228-31.

22. Mammana A, Baiardi S, Rossi M, Franceschini A, Donadio V, Capellari S, et al. Detection of prions in skin punch biopsies of Creutzfeldt-Jakob disease patients. Ann Clin Transl Neurol. 2020;7:559-64.

23. Andreoletti O, Orge L, Benestad SL, Beringue V, Litaise C, Simon S, et al. Atypical/Nor98 scrapie infectivity in sheep peripheral tissues. PLoS Pathog. 2011;7:e1001285.

24. Fediaevsky A, Maurella C, Noremark M, Ingravalle F, Thorgeirsdottir S, Orge $L$, et al. The prevalence of atypical scrapie in sheep from positive flocks is not higher than in the general sheep population in 11 European countries. BMC Vet Res. 2010;6:9.

25. Fediaevsky A, Tongue SC, Noremark M, Calavas D, Ru G, Hopp P. A descriptive study of the prevalence of atypical and classical scrapie in sheep in 20 European countries. BMC Vet Res. 2008;4:19.

26. Nodelijk G, van Roermund HJ, van Keulen LJ, Engel B, Vellema P, Hagenaars TJ. Breeding with resistant rams leads to rapid control of classical scrapie in affected sheep flocks. Vet Res. 2011;42:5.

27. Tamguney G, Richt JA, Hamir AN, Greenlee JJ, Miller MW, Wolfe LL, et al. Salivary prions in sheep and deer. Prion. 2012;6:52-61.

28. Hampton T. Prions found in deer body fluids. JAMA. 2006;296:2543.

29. Henderson DM, Davenport KA, Haley NJ, Denkers ND, Mathiason CK, Hoover EA. Quantitative assessment of prion infectivity in tissues and body fluids by real-time quaking-induced conversion. J Gen Virol. 2015;96:210-9.

30. Haley NJ, Mathiason CK, Carver S, Zabel M, Telling GC, Hoover EA. Detection of chronic wasting disease prions in salivary, urinary, and intestinal tissues of deer: potential mechanisms of prion shedding and transmission. J Virol. 2011;85:6309-18.

31. Safar JG, Lessard P, Tamguney G, Freyman Y, Deering C, Letessier $F$, et al. Transmission and detection of prions in feces. J Infect Dis. 2008;198:81-9.

32. Pritzkow S, Morales R, Moda F, Khan U, Telling GC, Hoover E, et al. Grass plants bind, retain, uptake, and transport infectious prions. Cell Rep. 2015;11:1168-75.

33. Almberg ES, Cross PC, Johnson CJ, Heisey DM, Richards BJ. Modeling routes of chronic wasting disease transmission: environmental prion persistence promotes deer population decline and extinction. PLoS ONE. 2011;6:e19896.

34. Maddison BC, Baker CA, Terry LA, Bellworthy SJ, Thorne L, Rees HC, et al. Environmental sources of scrapie prions. J Virol. 2010;84:11560-2.

35. Johnson CJ, Pedersen JA, Chappell RJ, McKenzie D, Aiken JM. Oral transmissibility of prion disease is enhanced by binding to soil particles. PLOS Pathog. 2007:3:e93.

36. Miller MW, Williams ES, Hobbs NT, Wolfe LL. Environmental sources of prion transmission in mule deer. Emerg Infect Dis. 2004;10:1003-6.

37. Rivera NA, Brandt AL, Novakofski JE, Mateus-Pinilla NE. Chronic wasting disease in cervids: prevalence, impact and management strategies. Vet Med (Auckl). 2019;10:123-39.

38. Baeten LA, Powers BE, Jewell JE, Spraker TR, Miller MW. A natural case of chronic wasting disease in a free-ranging moose (Alces alces shirasi). J Wildl Dis. 2007:43:309-14.

39. Chronic Wasting Disease Alliance C-IO. IL_Chronic wasting disease (CWD) found in a captive reindeer in Northern Illinois 2018. http:// cwd-info.org/il-chronic-wasting-disease-cwd-found-in-a-captive-reind eer-in-northern-illinois/. Accessed 28 Sept 2021.

40. Bartz JC. Environmental and host factors that contribute to prion strain evolution. Acta Neuropathol. 2021;142:5-16. 
41. Meyerett-Reid C, Wyckoff AC, Spraker T, Pulford B, Bender H, Zabel $M D$. De novo generation of a unique cervid prion strain using protein misfolding cyclic amplification. mSphere. 2017;2:e00372.

42. Gielbert A, Davis LA, Sayers AR, Hope J, Gill AC, Sauer MJ. High-resolution differentiation of transmissible spongiform encephalopathy strains by quantitative $\mathrm{N}$-terminal amino acid profiling (N-TAAP) of PK-digested abnormal prion protein. J Mass Spectrom. 2009;44:384-96.

43. Collinge J, Clarke AR. A general model of prion strains and their pathogenicity. Science. 2007;318:930-6.

44. Sigurdson CJ, Manco G, Schwarz P, Liberski P, Hoover EA, Hornemann S, et al. Strain fidelity of chronic wasting disease upon murine adaptation. J Virol. 2006:80:12303-11.

45. Bruce M, Chree A, McConnell I, Foster J, Pearson G, Fraser H. Transmission of bovine spongiform encephalopathy and scrapie to mice: strain variation and the species barrier. Philos Trans R Soc Lond B Biol Sci. 1994:343:405-11.

46. Bessen RA, Marsh RF. Distinct PrP properties suggest the molecular basis of strain variation in transmissible mink encephalopathy. J Virol. 1994;68:7859-68.

47. Bruce ME. Scrapie strain variation and mutation. Br Med Bull. 1993:49:822-38

48. Nonno R, Di Bari MA, Cardone F, Vaccari G, Fazzi P, Dell'Omo G, et al. Efficient transmission and characterization of Creutzfeldt-Jakob disease strains in bank voles. PLoS Pathog. 2006:2:e12.

49. Watts JC, Giles K, Patel S, Oehler A, DeArmond SJ, Prusiner SB. Evidence that bank vole PrP is a universal acceptor for prions. PLOS Pathog. 2014:10:e1003990.

50. Tamguney G, Giles K, Bouzamondo-Bernstein E, Bosque PJ, Miller MW, Safar J, et al. Transmission of elk and deer prions to transgenic mice. J Virol. 2006;80:9104-14.

51. Browning SR, Mason GL, Seward T, Green M, Eliason GA, Mathiason $C$, et al. Transmission of prions from mule deer and elk with chronic wasting disease to transgenic mice expressing cervid PrP. J Virol. 2004;78:13345-50.

52. Weissmann C, Fischer M, Raeber A, Bueler H, Sailer A, Shmerling D, et al. The use of transgenic mice in the investigation of transmissible spongiform encephalopathies. Int J Exp Pathol. 1996;77:283-93.

53. Race RE, Raines A, Baron TG, Miller MW, Jenny A, Williams ES. Comparison of abnormal prion protein glycoform patterns from transmissible spongiform encephalopathy agent-infected deer, elk, sheep, and cattle. J Virol. 2002;76:12365-8.

54. Benestad SL, Mitchell G, Simmons M, Ytrehus B, Vikoren T. First case of chronic wasting disease in Europe in a Norwegian free-ranging reindeer. Vet Res. 2016:47:88.

55. Nonno R, Di Bari MA, Pirisinu L, D’Agostino C, Vanni I, Chiappini B, et al. Studies in bank voles reveal strain differences between chronic wasting disease prions from Norway and North America. Proc Natl Acad Sci U S A. 2020;117:31417-26

56. Pirisinu L, Tran L, Chiappini B, Vanni I, Di Bari MA, Vaccari G, et al. Nove type of chronic wasting disease detected in moose (Alces alces). Norway Emerg Infect Dis. 2018:24:2210-8.

57. Våge J, Hopp P, Vikøren T, Madslien K, Tarpai A, Moldal T, et al. The surveillance programme for Chronic Wasting Disease (CWD) in free ranging and captive cervids in Norway. ISSN 1894-5678. Norwegian Veterinary Institute and Norwegian Food Safety Authority; 2020. Contract No.: ISSN 1894-5678.

58. Rolandsen CM, Våge J, Hopp P, Benestad SL, Mysterud A, Viljugrein H, et al. Kartlegging av skrantesjuke (Chronic Wasting Disease-CWD) i 2016 og 2017. NINA Rapport 1522Neterinærinstituttet Rapport 13 2018. 70 s.; 2018.

59. Rolandsen CM, Våge J, Hopp P, Benestad SL, Viljugrein H, Solberg EJ, et al. Kartlegging og overvåking av skrantesjuke (Chronic Wasting Disease - CWD) 2016-2018. NINA Rapport 1711/Neterinærinstituttet rapport 20 2019.; 2019.

60. Rolandsen CM, Våge J, Hopp P, Benestad SL, Viljugrein H, Solberg EJ, et al. Kartlegging og overvåking av skrantesjuke (Chronic Wasting Disease - CWD) 2016-2019. NINA Rapport 1818 / Veterinærinstituttet rapport 8, 2020. 44 s.: NINA Rapport 1818/Neterinærinstituttet rapport 8, 2020. 44 s.; 2020.

61. NVI. Norwegian Veterinary Institute CWD test statistics. http://apps. vetinst.no/skrantesykestatistikk/NO/\#omrade. Accessed 1 Apr 2021.
62. COMMISSION DECISION of 19 March 2007 on a survey for chronic wasting disease in cervids (notified under document number C(2007) 860) (Text with EEA relevance) (2007/182/EC). Official Journal of the European Union 2007

63. Surveillance of infectious diseases in animals and humans in Sweden 2016. National Veterinary Institute (SVA), Uppsala, Sweden; 2016. Contract No.: ISSN 1654-7098.

64. Surveillance of infectious diseases in animals and humans in Sweden 2019. National Veterinary Institute (SVA), Uppsala, Sweden; 2019. Report No.: 1654-7098.

65. EFSA. Panel on Biological Hazards (BIOHAZ); (2010). Scientific Opinion on the results of the EU survey for Chronic Wasting Disease (CWD) in cervids. EFSA J 2010; 8: 29 pp.

66. EFSA. Scientific opinion on the results of the EU survey for Chronic Wasting Disease (CWD) in cervids. EFSA J. 2010;8:1-29.

67. Ricci A, Allende A, Bolton D, Chemaly M, Davies R, Fernandez Escamez PS, et al. Chronic wasting disease (CWD) in cervids. EFSA J. 2017;15:e04667.

68. Commission Regulation (EU) 2017/1972 of 30 October 2017 amending Annexes I and III to Regulation (EC) No 999/2001 of the European Parliament and of the Council as regards a surveillance programme for chronic wasting disease in cervids in Estonia, Finland, Latvia, Lithuania, Poland and Sweden and repealing Commission Decision 2007/182/EC; 2017.

69. EFSA. The European Union summary report on surveillance for the presence of transmissible spongiform encephalopathies (TSE) in 2018. EFSA J. 2019:17:e05925.

70. Maraud S, Roturier S. Chronic Wasting Disease (CWD) in sami reindeer herding: the socio-political dimension of an epizootic in an indigenous context. Animals (Basel). 2021;11:297.

71. Koutsoumanis K, Allende A, Alvarez-Ordonez A, Bolton D, Bover-Cid S, Chemaly $M$, et al. Update on chronic wasting disease (CWD) III. EFSA J. 2019:17:e05863.

72. VKM. CWD in Norway - a state of emergency for the future of cervids (Phase II). Opinion of the panel on Biological Hazards; 2017. p. 1-125.

73. VKM. Factors that can contribute to spread of CWD-an update on the situation in Nordfjella. Opinion of the panel of biological hazards. ISBN: 978-82-8259-316-8. Norwegian Scientific Committee for Food and Environmenmt. 2018. p. 1-92.

74. Miller MW, Conner MM. Epidemiology of chronic wasting disease in free-ranging mule deer: spatial, temporal, and demographic influences on observed prevalence patterns. J Wildl Dis. 2005:41:275-90.

75. Heisey DM, Osnas EE, Cross PC, Joly DO, Langenberg JA, Miller MW. Linking process to pattern: estimating spatiotemporal dynamics of a wildlife epidemic from cross-sectional data. Ecol Monogr. 2010;80:221-40.

76. Mysterud A, Madslien K, Viljugrein H, Vikøren T, Andersen R, Güere ME, et al. The demographic pattern of infection with chronic wasting disease in reindeer at an early epidemic stage. Ecosphere. 2019;10:e02931.

77. Mysterud A, Hopp P, Alvseike KR, Benestad SL, Nilsen EB, Rolandsen $C M$, et al. Hunting strategies to increase detection of chronic wasting disease in cervids. Nat Commun. 2020;11:4392.

78. Viljugrein H, Hopp P, Benestad SL, Nilsen EB, Våge J, Tavornpanich S, et al. A method that accounts for differential detectability in mixed samples of long-term infections with applications to the case of chronic wasting disease in cervids. Methods Ecol Evol. 2019;10:134-45.

79. Mysterud A, Strand O, Rolandsen CM. Efficacy of recreational hunters and marksmen for host culling to combat chronic wasting disease in reindeer. Wildl Soc Bull. 2019;43:683-92.

80. Wik L, Mikko S, Klingeborn M, Steen M, Simonsson M, Linne T. Polymorphisms and variants in the prion protein sequence of European moose (Alces alces), reindeer (Rangifer tarandus), roe deer (Capreolus capreolus) and fallow deer (Dama dama) in Scandinavia. Prion. 2012;6:256-60.

81. Peletto S, Perucchini M, Acin C, Dalgleish MP, Reid HW, Rasero R, et al. Genetic variability of the prion protein gene (PRNP) in wild ruminants from Italy and Scotland. J Vet Sci. 2009;10:115-20.

82. Robinson AL, Williamson H, Guere ME, Tharaldsen H, Baker K, Smith SL, et al. Variation in the prion protein gene (PRNP) sequence of wild deer in Great Britain and mainland Europe. Vet Res. 2019;50:59. 
83. Pitarch JL, Raksa HC, Arnal MC, Revilla M, Martinez D, Fernandez de Luco $D$, et al. Low sequence diversity of the prion protein gene (PRNP) in wild deer and goat species from Spain. Vet Res. 2018;49:33.

84. Mysterud A, Rolandsen CM. A reindeer cull to prevent chronic wasting disease in Europe. Nat Ecol Evol. 2018;2:1343-5.

85. Guere ME, Vage J, Tharaldsen H, Benestad SL, Vikoren T, Madslien K, et al. Chronic wasting disease associated with prion protein gene (PRNP) variation in Norwegian wild reindeer (Rangifer tarandus). Prion. 2020;14:1-10.

86. Spraker TR, Zink RR, Cummings BA, Wild MA, Miller MW, O'Rourke KI. Comparison of histological lesions and immunohistochemical staining of proteinase-resistant prion protein in a naturally occurring spongiform encephalopathy of free-ranging mule deer (Odocoileus hemionus) with those of chronic wasting disease of captive mule deer. Vet Pathol. 2002;39:110-9.

87. Spraker TR, Miller MW, Williams ES, Getzy DM, Adrian WJ, Schoonveld $G G$, et al. Spongiform encephalopathy in free-ranging mule deer (Odocoileus hemionus), white-tailed deer (Odocoileus virginianus) and Rocky Mountain elk (Cervus elaphus nelsoni) in northcentral Colorado. J Wildl Dis. 1997:33:1-6.

88. Williams ES, Young S. Neuropathology of chronic wasting disease of mule deer (Odocoileus hemionus) and elk (Cervus elaphus nelsoni). Vet Pathol. 1993;30:36-45.

89. Kreeger TJ, Montgomery DL, Jewell JE, Schultz W, Williams ES. Oral transmission of chronic wasting disease in captive Shira's moose. J Wildl Dis. 2006;42:640-5.

90. Foster JD, Dickinson AG. The unusual properties of $\mathrm{CH} 1641$, a sheeppassaged isolate of scrapie. Vet Rec. 1988;123:5-8.

91. Jeffrey M, Gonzalez L, Chong A, Foster J, Goldmann W, Hunter N, et al. Ovine infection with the agents of scrapie ( $\mathrm{CH} 1641$ isolate) and bovine spongiform encephalopathy: immunochemical similarities can be resolved by immunohistochemistry. J Comp Pathol. 2006;134:17-29.

92. Baron T, Bencsik A, Vulin J, Biacabe AG, Morignat E, Verchere J, et al. A C-terminal protease-resistant prion fragment distinguishes ovine "CH1641-like" scrapie from bovine classical and L-Type BSE in ovine transgenic mice. PLoS Pathog. 2008:4:e1000137.

93. Lezmi S, Martin S, Simon S, Comoy E, Bencsik A, Deslys JP, et al. Comparative molecular analysis of the abnormal prion protein in field scrapie cases and experimental bovine spongiform encephalopathy in sheep by use of Western blotting and immunohistochemical methods. J Virol. 2004;78:3654-62.

94. Stack MJ, Chaplin MJ, Clark J. Differentiation of prion protein glycoforms from naturally occurring sheep scrapie, sheep-passaged scrapie strains
(CH1641 and SSBP1), bovine spongiform encephalopathy (BSE) cases and Romney and Cheviot breed sheep experimentally inoculated with BSE using two monoclonal antibodies. Acta Neuropathol. 2002;104:279-86.

95. Bunnefeld N, Borger L, van Moorter B, Rolandsen CM, Dettki H, Solberg EJ, et al. A model-driven approach to quantify migration patterns: individual, regional and yearly differences. J Anim Ecol. 2011;80:466-76.

96. Agren EO, Soren K, Gavier-Widen D, Benestad SL, Tran L, Wall K, et al. First detection of chronic wasting disease in moose (Alces alces) in Sweden. J Wildl Dis. 2021;57:461-3.

97. Bekrefter atypisk skrantesjuke på hjort i Etne (Confirmed case of atypical CWD in a deer in Etne). [press release]. 24; 2021.

98. Vikoren T, Vage J, Madslien Kl, Roed KH, Rolandsen CM, Tran L, et al. First detection of chronic wasting disease in a wild red deer (Cervus elaphus) in Europe. J Wildl Dis. 2019;55:970-2.

99. Balachandran A, Harrington NP, Algire J, Soutyrine A, Spraker TR, Jeffrey $M$, et al. Experimental oral transmission of chronic wasting disease to red deer (Cervus elaphus elaphus): early detection and late stage distribution of protease-resistant prion protein. Can Vet J. 2010;51:169-78.

100. Schwabenlander MD, Culhane MR, Hall SM, Goyal SM, Anderson PL, Carstensen $\mathrm{M}$, et al. A case of chronic wasting disease in a captive red deer (Cervus elaphus). J Vet Diagn Invest. 2013;25:573-6.

101. Di Bari MA, Nonno R, Castilla J, D’Agostino C, Pirisinu L, Riccardi G, et al. Chronic wasting disease in bank voles: characterisation of the shortest incubation time model for prion diseases. PLoS Pathog. 2013;9:e1003219.

102. Medicine CJ. Prion strain mutation and selection. Science. 2010;328:1111-2.

103. Angers RC, Kang HE, Napier D, Browning S, Seward T, Mathiason C, et al. Prion strain mutation determined by prion protein conformational compatibility and primary structure. Science. 2010;328:1154-8.

104. Wadsworth JDF, Joiner S, Linehan JM, Jack K, Al-Doujaily H, Costa H, et al. Humanised transgenic mice are resistant to chronic wasting disease prions from Norwegian reindeer and moose. J Infect Dis. 2021. https://doi.org/10.1093/infdis/jiab033.

\section{Publisher's Note}

Springer Nature remains neutral with regard to jurisdictional claims in published maps and institutional affiliations.
Ready to submit your research? Choose BMC and benefit from:

- fast, convenient online submission

- thorough peer review by experienced researchers in your field

- rapid publication on acceptance

- support for research data, including large and complex data types

- gold Open Access which fosters wider collaboration and increased citations

- maximum visibility for your research: over $100 \mathrm{M}$ website views per year

At BMC, research is always in progress.

Learn more biomedcentral.com/submissions 